\title{
PENENTUAN DISTRIBUSI UKURAN PARTIKEL TEPUNG TERIGU DENGAN MENGGUNAKAN METODE PENGAPUNGAN BATANG (BUOYANCY WEIGHING-BAR METHOD)
}

\author{
Rondang Tambun, Nofriko Pratama, Ely, Farida Hanum \\ Departemen Teknik Kimia, Fakultas Teknik, Universitas Sumatera Utara, \\ Jl. Almamater Kampus USU, Medan 20155, Indonesia \\ Email : rondang_tambun@yahoo.com / rondang@usu.ac.id
}

\begin{abstract}
Abstrak
Penentuan distribusi ukuran partikel tepung terigu merupakan salah satu yang penting dalam industri pengolahan tepung terigu. Selama ini, berbagai cara dapat dilakukan untuk menentukan ukuran partikel tepung terigu seperti metode Andreasen pipette, sedimentation balance, centrifugal sedimentation, laser diffraction/ scattering, microscopy, Coulter counter dan lain sebagainya. Metode-metode tersebut di atas mempunyai kelebihan dan kekurangan, terutama masalah kekurangpraktisan, waktu ataupun masalah biaya. Metode Andreasen Pipette, sedimentation balance dan centrifugal sedimentation merupakan metode yang murah tetapi butuh waktu yang lama dan keahlian untuk mengoperasikannya. Sebaliknya, metode laser diffraction/scattering, microscopy dan Coulter counter merupakan metode yang sangat akurat dan cepat, tetapi memerlukan biaya yang sangat mahal. Pada penelitian ini, dikembangkan suatu metode terbaru yaitu Metode Pengapungan Batang (Buoyancy WeighingBar Method) untuk menentukan distribusi ukuran partikel tepung terigu. Metode ini mengukur distribusi ukuran partikel dengan menggunakan sebuah batang logam yang digantungkan pada cairan yang berisi butiran partikel tepung yang terdispersi pada cairan tersebut. Pada metode ini, perubahan densitas larutan yang terjadi karena perpindahan partikel tepung dalam suspensi (etanol/metanol) diukur berdasarkan perubahan massa batang logam yang digantung di dalam suspensi. Dari hasil penelitian diperoleh bahwa hasil yang diperoleh menggunakan Metode Pengapungan Batang sebanding dengan hasil yang diperoleh dengan Metode sedimentation balance.
\end{abstract}

Kata Kunci : daya apung, distribusi ukuran partikel, pengapungan batang, tepung terigu

\begin{abstract}
Particle size measurement of wheat flour is important in wheat flour industry. There are several methods have been used to measure particle size distribution (PSD) of wheat flour, such as Andreasen pipette method, sedimentation balance method, centrifugal sedimentation method. The disadvantages of these methods are that they are time consuming and require special skills. On the other hand, PSD can be analyzed using a different principle through laser diffraction/scattering methods, and coulter counter method. The laser diffraction/scattering and coulter counter methods produce highly accurate results within a shorter time, but the equipment is extremely expensive. Therefore, a simple and cost-effective new method to determine PSD is in high demand. In this study, we aim to develop a new method to measure the particle size distribution of wheat flour using a buoyancy weighing-bar method. In this method, the density change in a suspension due to particle migration (wheat flour) is measured by weighing buoyancy against a weighing-bar hung in the suspension (etanol/metanol), and the PSD is calculated using the length of the bar and the time-course change in the mass of the bar. This apparatus consists of an analytical balance with a hook for underfloor weighing, and a weighingbar, which is used to detect the density change in suspension. The result obtained show that the PSD of wheat flour measured by the buoyancy weighing-bar method is comparable to that determined by settling balance method.
\end{abstract}

Keywords : buoyancy, particle size distribution, weighing bar, wheat flour

\section{Pendahuluan}

Penentuan distribusi ukuran partikel tepung terigu merupakan salah satu metode yang penting dalam teknologi partikel dalam industri tepung terigu. Selama ini, berbagai cara sudah dilakukan untuk menentukan ukuran partikel [15]. Untuk sistem padat-cair, distribusi ukuran partikel diukur menggunakan diameter Stokes dengan mengukur kecepatan perpindahan partikel dalam larutan. Metode-metode yang menggunakan cara ini antara lain adalah Metode Andreasen Pipette [14], Metode Sedimentation Balance [6], Metode
Centrifugal Sedimentation [7], dan lain-lain. Metode-metode ini sangat murah dalam pengoperasiannya, tetapi membutuhkan waktu yang agak lama dan kurang praktis dalam penggunaannya. Pada sisi lain, berbagai metode dengan sistem berbeda juga telah ditemukan seperti Metode Laser Diffraction/Scattering [5], Microscopy [8] dan Metode Coulter Counter [18]. Pengoperasian metode-metode ini sangat praktis sekali dan hasil yang diperoleh sangat akurat dalam tempo yang singkat, tetapi harga peralatan yang dipakai sangat mahal. 
Untuk mengatasi masalah ini, sebuah metode yang sederhana, praktis dan murah sangat diperlukan. Metode terbaru yang sedang dikembangkan untuk mengatasi masalah tersebut Buoyancy Weighing-Bar Method (BWM). Metode ini telah terbukti dapat menentukan distribusi ukuran partikel pada Stokes region maupun pada Allen region untuk berbagai partikel seperti alumina, glass beads, silica sands, nylon beads, magnesite, calcium carbonate, glass bubbles, dan lain-lain. Metode ini pertama sekali dikembangkan oleh Obata, dkk. Mereka mengukur distribusi ukuran partikel dengan menggunakan sebuah batang logam yang digantungkan pada cairan yang berisi butiran partikel yang terdispersi pada cairan tersebut. Cara inilah yang disebut dengan Buoyancy Weighing-Bar Method (Metode Pengapungan Batang). Pada metode ini, perubahan densitas larutan yang terjadi karena perpindahan partikel diukur dari perubahan massa batang yang digantung di dalam suspensi $[2 ; 9-12]$.

Pada industri tepung terigu, penentuan distribusi ukuran partikel biasanya dilakukan menggunakan metode sedimentation balance, laser diffraction/scattering ataupun metode Coulter counter. Metode sedimentation balance tergolong metode yang rumit dan memerlukan waktu yang lama dalam pengoperasiannya, sementara metode laser diffraction/scattering dan metode Coulter counter ini tergolong metode yang sangat mahal, sehingga untuk mengatasi masalah ini dikaji pemakaian Metode Pengapungan Batang.

\section{Teori}

Pada dasarnya distribusi ukuran partikel yang diukur dengan Metode Pengapungan Batang sama dengan yang dipakai pada metode manometrik dan metode Oden Balance [13]. Secara grafik, kurva massa terhadap waktu pengendapan pada Metode Pengapungan Batang ini analog dengan kurva pressure drop terhadap superficial velocity pada fluidisasi $[1,3,4]$.

Gambar 1 mengillustrasikan skematik diagram dari pengendapan partikel. Volume batang dalam suspensi adalah $V_{\mathrm{B}}=A h$, dengan $A$ adalah luas permukaan dari batang pemberat dan $\mathrm{h}$ adalah panjang batang yang dicelupkan pada suspensi. Densitas dari pelarut (cairan) dilambangkan dengan $\rho_{\mathrm{L}}$, sedangkan densitas partikel dilambangkan dengan $\rho_{\mathrm{P}}$. konsentrasi mula-mula padatan dalam suspensi adalah $C o$ (kg-padatan $/ \mathrm{m}^{3}$-suspensi) [16,2]

Gambar 1(a) menunjukkan bahwa massa batang mula-mula yang mengapung pada kondisi awal tergantung pada partikel yang berada antara bagian atas batang dan bagian bawah batang dalam suspensi. Pada waktu pengendapan $t=0$, densitas mula-mula dari suspensi $\left(\rho_{\mathrm{S} 0}\right)$ adalah:

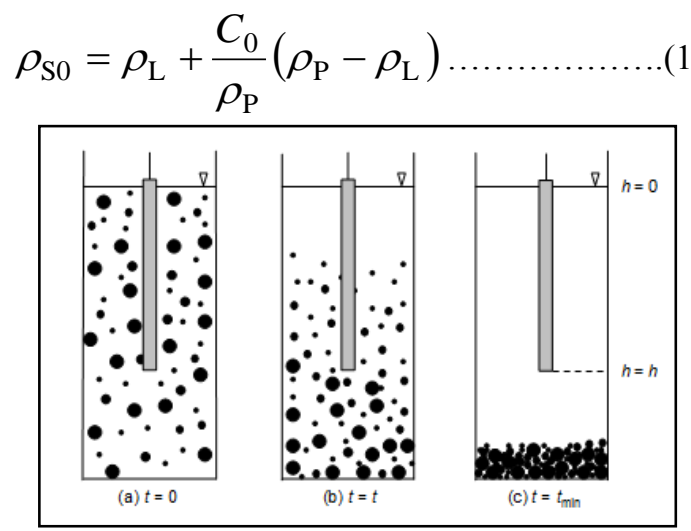

Gambar 1. Skematik Diagram Pengendapan Partikel

Massa batang mula-mula yang mengapung, $W_{\mathrm{B} 0}$ tergantung pada partikel pada suspensi dari permukaan sampai kedalaman $\mathrm{h}$, maka $W_{\mathrm{B} 0}$ dapat didefenisikan sebagai berikut :

$W_{\mathrm{B} 0}=V_{\mathrm{B}} \rho_{\mathrm{S} 0}$

Pada kondisi mula-mula, massa batang dalam suspensi adalah

$G_{\mathrm{B} 0}=V_{\mathrm{B}} \rho_{\mathrm{B}}-W_{\mathrm{B} 0}=V_{\mathrm{B}}\left(\rho_{\mathrm{B}}-\rho_{\mathrm{S} 0}\right)$

dimana, $\rho_{\mathrm{B}}$ adalah densitas dari batang. Gambar 1(b) menunjukkan konsentrasi suspensi (C) semakin menurun dari waktu ke waktu, karena partikel yang besar sudah mengendap. Densitas suspensi $\rho_{\text {St }}$, massa pengapungan batang $W_{B t}$, dan massa nyata dari batang $G_{\mathrm{Bt}}$ di dalam suspensi pada $\mathrm{t}=\mathrm{t}$ diberikan sesuai dengan persamaan berikut.

$$
\begin{aligned}
& \rho_{S t}=\rho_{L}+\frac{\left(\rho_{P}-\rho_{L}\right)}{\rho_{P}} C \\
& W_{B t}=V_{B} \cdot \rho_{S t} \\
& G_{B t}=V_{B} \cdot \rho_{B}-W_{B t}=V_{B} \cdot \rho_{B}-V_{B} \cdot \rho_{S t}=V_{B}\left(\rho_{B}-\rho_{S t}\right)
\end{aligned}
$$

Gambar 1(c), pada $\mathrm{t}=\sim$, konsentrasi suspensi adalah 0, karena semua partikel, baik besar maupun kecil sudah mengendap. Densitas suspensi $\rho_{\mathrm{S} \infty}$, massa pengapungan batang $W_{B \infty}$, dan massa nyata dari batang $G_{\mathrm{B} \infty}$ di dalam suspensi pada $\mathrm{t}=\sim$ diberikan sesuai dengan persamaan berikut.

$$
\begin{aligned}
& \rho_{S \infty}=\rho_{L} \ldots \ldots \ldots \ldots \ldots \ldots \ldots \ldots \ldots \ldots \ldots \ldots \ldots \ldots \ldots \ldots \ldots \ldots \ldots \ldots \ldots \ldots \ldots \ldots \ldots \ldots \ldots \\
& W_{B \infty}=V_{B} \cdot \rho_{L} \ldots \ldots \ldots \ldots \\
& G_{B \infty}=V_{B} . \rho_{B}-W_{B \infty}=V_{B}\left(\rho_{B}-\rho_{L}\right)
\end{aligned}
$$

Persamaan 10 menunjukkan neraca massa partikel dalam suspensi [15].

$C_{0}-C=C_{0} \int_{x_{i}}^{x_{\max }} f(x) d x+C_{0} \int_{x_{\min }}^{x_{i}} \frac{v(x) t}{h} f(x) d x \cdots$ 
Dari persamaan (2), (5), (8) dan (10), diperoleh:

$W_{0}-W=\left(W_{0}-W_{\infty}\right) \int_{x_{i}}^{x_{\max }} f(x) d x+\left(W_{0}-W_{\infty}\right) \int_{x_{\min }}^{x_{i}} \frac{v(x) t}{h} f(x) d x$

dimana $v(x)$ adalah kecepatan pengendapan, $\mathrm{f}(\mathrm{x})$ adalah frekuensi massa partikel berukuran $\mathrm{x}$. Diferensial persamaan 11 terhadap waktu t, maka akan diperoleh :

$$
-\frac{d W}{d t}=\left(W_{0}-W_{\infty}\right) \int_{x_{\min }}^{x_{i}} \frac{v(x)}{h} f(x) d x \ldots \ldots \ldots
$$

Dari persamaan 11 dan 12 ,

$$
W_{\mathrm{B} t}=W_{\mathrm{R} t}+\left(\frac{d W_{\mathrm{B} t}}{d t}\right) t
$$

dimana $W_{R t}$ adalah massa partikel yang lebih besar dari partikel berukuran $\mathrm{x}$,

$$
W_{0}-\left(W_{0}-W_{\infty}\right) \int_{x_{i}}^{x_{\max }} f(x) d x \text {. }
$$

Kombinasi persamaan 6 dan 13 akan menghasilkan :

$G_{B t}=V_{B} \cdot \rho_{B}-W_{R t}+\left(\frac{d G_{B t}}{d t}\right) t=G_{R t}+\left(\frac{d G_{B t}}{d t}\right) t \cdots \ldots$

Dimana,

$$
G_{R t}=V_{B} \cdot \rho_{B}-W_{R t},
$$

$\frac{d G_{B t}}{d t}=-\frac{d W_{B t}}{d t}$, karena penurunan massa batang sesuai dengan penurunan massa pengapungan batang. Nilai $G_{R t}$ dihitung dari slope persamaan 14. Hubungan kumulatif massa oversize, $\mathrm{R}(x)$ dan kumulatif massa undersize, $\mathrm{D}(x)$ adalah,

$$
R(x)=\int_{x_{i}}^{x_{\max }} f(x) d x=\frac{G_{R t}-G_{B 0}}{G_{B \infty}-G_{B 0}}=1-D(x)
$$

Ukuran partikel $\mathrm{x}$ diekspresikan dengan menggunakan persamaan Stokes:

$$
x=\sqrt{\frac{18 \mu_{\mathrm{L}} v(x)}{g\left(\rho_{\mathrm{P}}-\rho_{\mathrm{L}}\right)}}
$$

dimana $g$ adalah percepatan gravitasi dan $\mu_{\mathrm{L}}$ adalah viskositas larutan. Kecepatan pengendapan $v(x)$ partikel dihitung sesuai dengan persamaan 17 .

$$
v(x)=\frac{h}{t}
$$

Dimana $h$ adalah panjang batang yang terapung di dalam cairan dan $t$ adalah waktu pengendapan. Ukuran partikel $x$ yang dihasilkan pada persamaan 17 merupakan diameter Stokes. Hal ini membuktikan bahwa teori pada Metode Pengapungan Batang ini mirip dengan metode sedimentation balance [13].

Gambar 2 mengillustrasikan metode perhitungan distribusi ukuran partikel yang mengendap dengan menggunakan Metode Pengapungan Batang. Gambar kanan atas menunjukkan perubahan massa batang sebagai fungsi waktu, sementara gambar kanan bawah menunjukkan hubungan waktu dengan kebalikan ukuran partikel. Dari persamaan 16 dan 17, waktu sebanding dengan kuadrat kebalikan dari ukuran partikel. Jadi dalam metode ini, ukuran partikel $x$ dapat dihitung pada setiap waktu $t$, sementara $G_{\mathrm{Rt}}$ secara simultan dapat dihitung dari slope, sesuai dengan persamaan 14. Kumulatif massa undersize, $\mathrm{D}(x)$ dapat dihitung dengan persamaan 15. Pada gambar kiri atas, distribusi ukuran partikel diperoleh dari perhitungan ukuran partikel $x$ dan $\mathrm{D}(x)[2,11]$.

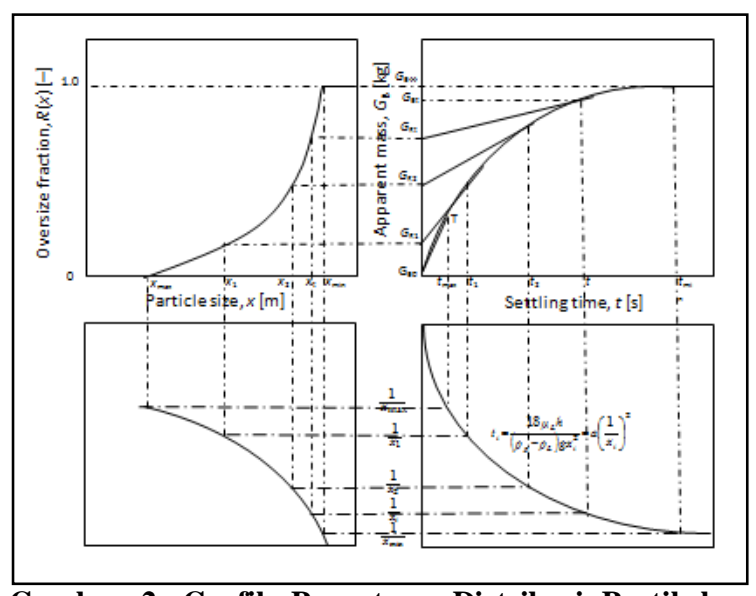

Gambar 2. Grafik Penentuan Distribusi Partikel dengan Metode Pengapungan Batang

\section{Metodologi Penelitian}

Pada penelitian ini, kami melakukan serangkaian percobaan penentuan distribusi ukuran partikel dengan Metode Pengapungan Batang. Material sampel yang diteliti adalah tepung terigu (Cap Segi Tiga Biru). Etanol dan metanol digunakan sebagai fase cairan. Air tidak dianjurkan digunakan pada penelitian ini karena tepung terigu tidak akan terpisah dengan baik di dalam air. Konsentrasi suspensi adalah $10 \mathrm{~kg} / \mathrm{m}^{3}$ ( \pm 1 wt.\%) [17]. Suhu ruangan dan suhu cairan adalah 298 K (suhu kamar). Semua suspensi akan diaduk sebelum dilakukan pengukuran. Lama pengukuran adalah 2 jam. Pada penelitian ini, distribusi ukuran partikel diukur berdasarkan hukum Stokes. Sebagai pembanding dari hasil penelitian ini dilakukan dengan menggunakan metode sedimentation/settling balance. Ilustrasi rangkaian peralatan yang digunakan dapat dilihat pada Gambar 3.

Batang yang digunakan terbuat dari aluminium dengan diameter $10 \mathrm{~mm}$ dan panjang $200 \mathrm{~mm}$, densitas : $2.70 \times 10^{3} \mathrm{~kg} / \mathrm{m}^{3}$. Neraca analitik (4 desimal) mempunyai pengait di bagian bawahnya untuk menggantung batang aluminium. Data akan direkam setiap interval 60 detik.

Untuk menyiapkan suspensi, $1000 \mathrm{ml}$ cairan dan partikel dicampur dalam gelas ukur. Dengan mengunakan tali/benang yang sangat ringan, batang digantung dari bawah neraca analitik. Setelah diaduk dengan pengaduk khusus, 
batang dimasukkan ke dalam suspensi, dan dicatat sebagai $\mathrm{t}=0$ detik. Hal ini berlangsung selama 2 jam. Setelah pengukuran selesai, distribusi ukuran partikel diukur berdasarkan teori di atas.

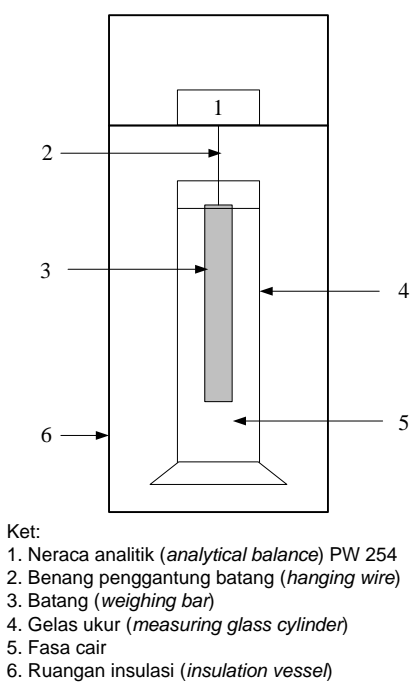

Gambar 3. Skematik dari Peralatan Eksperimen

\section{Hasil Penelitian}

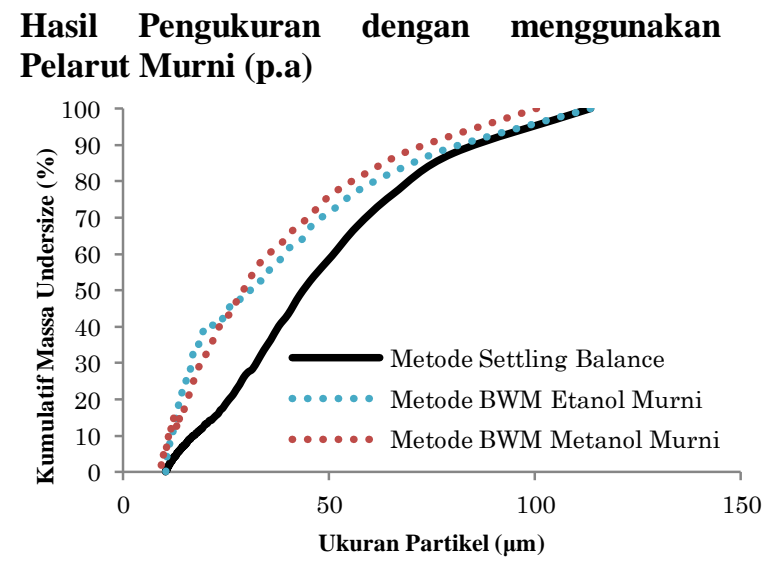

Gambar 4. Distribusi Ukuran Partikel Tepung Terigu Menggunakan Pelarut Murni

Gambar 4 memberikan gambaran bahwa penggunaan etanol murni lebih baik daripada metanol murni. Sebelum percobaan, tepung terigu diayak menggunakan ayakan 140 mesh (125 $\mu \mathrm{m})$. Pada penelitian yang dilakukan, metode settling balance menghasilkan distribusi ukuran partikel tepung terigu dalam rentang sekitar $10-113 \mu \mathrm{m}$. Hasil ini menunjukkan bahwa rentang pengukuran sebanding dengan yang dihasilkan Metode Pengapungan Batang (BWM).

\section{Hasil Pengukuran dengan menggunakan Etanol Teknis \\ Gambar 5 memberikan gambaran bahwa penggunaan etanol murni lebih baik daripada}

etanol teknis. Semakin tinggi konsentrasi etanol, maka distribusi hasil pengukuran partikel akan semakin baik. Pada berbagai konsentrasi ini, hasil penelitian menunjukkan bahwa rentang ukuran partikel yang diukur dengan metode BWM sebanding dengan hasil yang diperoleh dengan menggunakan metode settling balance.

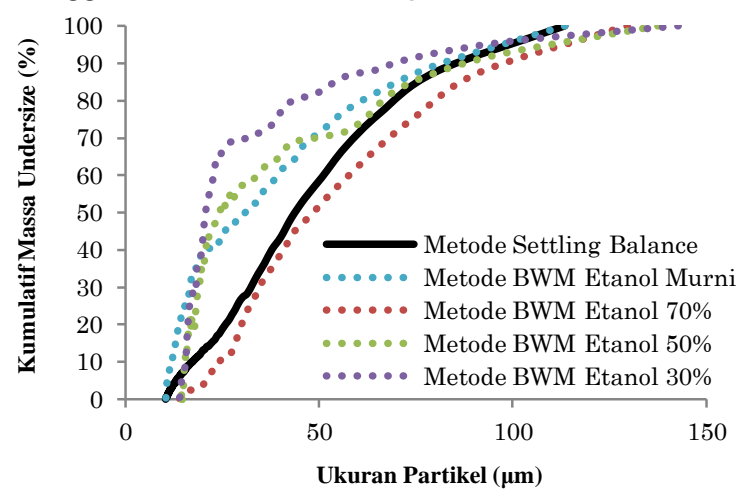

Gambar 5. Distribusi Ukuran Partikel Tepung Terigu Menggunakan Etanol Teknis

\section{Hasil Pengukuran dengan menggunakan Metanol Teknis}

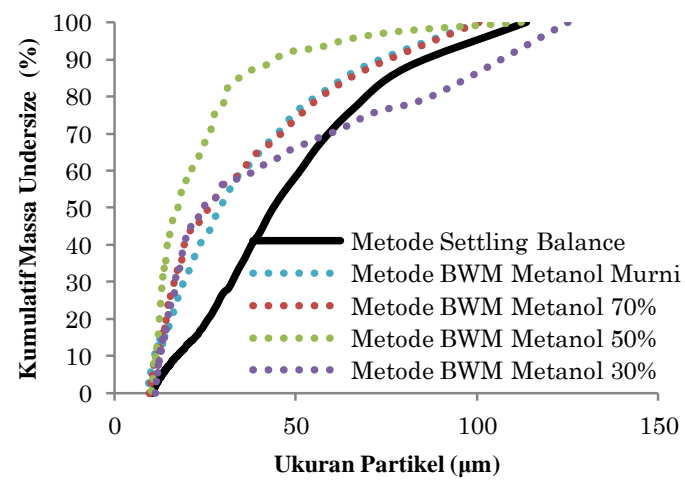

Gambar 6. Distribusi Ukuran Partikel Tepung Terigu Menggunakan Metanol Teknis

Gambar 6 memberikan gambaran bahwa penggunaan metanol murni lebih baik daripada metanol teknis. Semakin tinggi konsentrasi metanol, maka distribusi hasil pengukuran partikel akan semakin baik. Pada berbagai konsentrasi ini, hasil penelitian menunjukkan bahwa rentang ukuran partikel yang diukur dengan metode BWM sebanding dengan hasil yang diperoleh dengan menggunakan metode settling balance.

\section{Kesimpulan}

Hasil penelitian ini memberikan kesimpulan sebagai berikut :

1. Pelarut etanol memberikan hasil lebih baik daripada pelarut metanol pada penentuan distribusi ukuran partikel tepung terigu menggunakan metode BWM, dan semakin tinggi konsentrasi etanol/metanol yang digunakan, maka hasil distribusi ukuran 
partikel yang diperoleh akan semakin baik.

2. Rentang hasil pengukuran distribusi ukuran partikel dengan menggunakan metode BWM ini sebanding dengan rentang hasil yang diperoleh dengan menggunakan settling balance.

\section{Ucapan Terima Kasih}

Terimakasih kami sampaikan kepada Direktorat Jenderal Pendidikan Tinggi (DIKTI), Kementerian Pendidikan dan Kebudayaan atas dukungan dana yang diberikan untuk pelaksanaan penelitian ini melalui Hibah Penelitian Fundamental tahun 2014.

\section{Daftar Pustaka}

[1] E. Obata, Watanabe and N. Endo, Measurement of size and size distribution of particles by fluidization, Journal of Chemical Engineering of Japan, 15, 23-28, 1982.

[2] E. Obata, Y. Ohira and M. Ohta, New measurement of particle size distribution by buoyancy weighing-bar method, Powder Technology, 196, 163-168, 2009.

[3] E. Obata and H. Watanabe, Measurement of particle sizes by fluidization, Encyclopedia of Fluid Mechanics, vol. 4, Gulf Publishing, Houston, pp. 221-236, 1986.

[4] E. Obata and K. Ando, Particle size measurements by fluidization: From laminar flow region to the turbulent flow region, Encyclopedia of Fluid Mechanics, Supplement 2, Gulf Publishing, Houston, pp. 169-189, 1993.

[5] H. Minoshima, K. Matsushima and K. Shinohara, Experimental study on size distribution of granules prepared by spray drying: the case of a dispersed slurry containing binder, Kagaku Kogaku Ronbunshu, 31, 102-107, 2005.

[6] K. Fukui, H. Yoshida, M. Shiba and Y. Tokunaga, Investigation about data reduction and sedimentation distance of sedimentation balance method, Journal of Chemical Engineering of Japan, 33, 393399, 2000.

[7] M. Arakawa, G. Shimomura, A. Imamura, N. Yazawa, T. Yokoyama and N. Kaya, A New apparatus for measuring particle size distribution based on centrifugal sedimentation, Journal of the Society of Materials Science of Japan, 33, 1141-1145, 1984.
[8] M. Kuriyama, H. Tokanai and E. Harada, Maximum stable drop size of pseudoplastic dispersed-phase in agitation dispersion, Kagaku Kogaku Ronbunshu, 26, 745-748, 2000.

[9] R. Tambun, T. Motoi, M. Shimadzu, Y. Ohira and E. Obata, Size distribution measurement of floating particles in the Allen region by a buoyancy weighing-bar method, Advanced Powder Technology, 22, 548-552, 2011.

[10] R. Tambun, K. Nakano, M. Shimadzu, Y. Ohira and E. Obata, Sizes Influences of Weighing Bar and Vessel in the Buoyancy Weighing-Bar Method on Floating Particle Size Distribution Measurements, Advanced Powder Technology, 23, 855-860, 2012.

[11] R. Tambun, Y. Ohira and E. Obata, Graphical analogy of particle size distribution among Andreasen pipette, settling balance, fluidization-curve and buoyancy weighing-bar methods, Proceeding of the $13^{\text {th }}$ Asia Pacific Confederation of Chemical Engineering Congress, Taipei, Taiwan, 2010.

[12] R. Tambun, M. Shimadzu, Y. Ohira and E. Obata, Definition of the New Mean Particle Size based on the Settling Velocity in Liquid, Journal of Chemical Engineering of Japan, 45, 279-284, 2012.

[13] S. Odén, The size distribution of particles in soils and the experimental methods of obtaining them, Soil Science, 19, 1-35, 1925.

[14] Society of Chemical Engineering of Japan, Chemical Engineering Handbook, $5^{\text {th }}$ edition, Maruzen, Tokyo, Japan, pp. 224-231, 1988.

[15] T. Allen, Particle Size Measurement, Fourth edition, Chapman and Hall, London, pp. 345-355, 1990.

[16] T. Motoi, Y. Ohira and E. Obata, Measurement of the floating particle size distribution by buoyancy weighing-bar method, Powder Technology, 201, 283-288, 2010.

[17] Y. Ohira, K. Furukawa, R. Tambun, M. Shimadzu and E. Obata, Buoyancy weighing-bar method: A particle size distribution measurement using new settling method, Journal of the Sedimentological Society of Japan, 69, 17-26, 2010.

[18] Y. Ohira, H. Takahashi, M. Takahashi and K. Ando, Wall heat transfer in a double-tube coal-slurry bubble column, Kagaku Kogaku Ronbunshu, 30, 360-367, 2004. 